\title{
Discrete Design Optimization Of A 3-Phase Squirrel Cage Type Induction Motor
}

\author{
Pritish Kumar Ghosh ${ }^{1 *}$, Pradip Kumar Sadhu \\ ${ }^{1,2}$ Department of Electrical Engineering IIT (ISM), Dhanbad \\ Corresponding Author Email: pritishghosh80@gmail.com
}

\begin{abstract}
The broad application of modern industrial drives is implemented as a three-phase squirrelcage type induction motor. The outpaced their predecessor the D.C motors for various advantages they have. Slip-ring or phase-wound types are used as adjustable-speed drives. Later arrival of power-electronic equipment's cage-type motors are additionally being utilized as customizable speed drives. The single-phase motors are also widely used for running small machineries and domestic appliances. The total expenses for these motors constitute the largest fraction of the total investment at the consumer end. Therefore, they must be developed cost-optimally. At the same time, they must correspond to the criteria defined by the client or the legislative requirements enforced by the authorities. If the design is produced according to recommendations offered in the text-books, we may expect to get merely a workable solution but not the costoptimum solution. For job work, it is cheap to utilize standard stampings since this approach avoids the cost of dies which is rather expensive. The paper presents an iterative procedure to get the cost-optimal solution subject to usual design constraints, using standard stampings available in the market. A case study has been made on its basis and optimal design approach saves money.
\end{abstract}

Keywords: Analytic design, optimal design, Cost function, 3-phase Squirrel Cage Induction motor

\section{INTRODUCTION}

Standard laminations are commonly utilized in the manufacturing of transformers and induction motors. It is more cost-effective to do so. If laminations are designed freely, the die-set needed to fabricate the laminations is relatively expensive. Purchasing die-sets for laminations is not cost effective if the order is just for a few machines. The usual practice is to use standard stampings for the same. Standard stampings of various sizes are available in the Indian market. Once upon a time Shankey wing of M/S Guest, Keen and Williams dominated the market of stampings. Now several other companies like M/S Debidayal etc. makes mass production of stampings. Designs conforming to standard stampings and standard frames cannot be made by following the test-book procedure. Specially constructed programmes are required for their design.

Table1.SYMBOLS AND ACRONYMS

\begin{tabular}{|c|l|}
\hline SYMBOLS & \multicolumn{1}{c|}{ ACRONYMS } \\
\hline $\boldsymbol{G}$ & Rating of machine in Kw. \\
\hline $\boldsymbol{a} \boldsymbol{c}$ & Amp.Conductor/m. \\
\hline $\boldsymbol{B}_{\boldsymbol{a} v}$ & Average flux-density in the air-gap, Tesla. \\
\hline $\boldsymbol{K}_{\boldsymbol{p}}, \boldsymbol{K}_{\boldsymbol{b}}$ & Pitch/breadth factor of stator winding. \\
\hline $\boldsymbol{V}_{\boldsymbol{s}} / \boldsymbol{V}_{\boldsymbol{p}}$ & Stator line/phase voltage, V. \\
\hline $\boldsymbol{I}_{\boldsymbol{s}} / \boldsymbol{I}_{\boldsymbol{p}}$ & Stator line/phase current, A. \\
\hline $\boldsymbol{\delta}_{\boldsymbol{s}} / \boldsymbol{\delta}_{\boldsymbol{r}}$ & Stator/rotor current density, A/mm ${ }^{2}$. \\
\hline $\boldsymbol{K}_{\boldsymbol{s}}, \boldsymbol{K}_{\boldsymbol{w}}$ & Stacking factor, copper space factor. \\
\hline $\boldsymbol{D}_{\boldsymbol{b}} \boldsymbol{D}_{\boldsymbol{o}}$ & Stator bore/outer diameter. \\
\hline $\boldsymbol{D}_{\boldsymbol{o}}, \boldsymbol{D}_{\boldsymbol{i}}$ & Stator outer/Rotor inner diameter. \\
\hline $\boldsymbol{D}_{\boldsymbol{r}}, \boldsymbol{D}_{\boldsymbol{i}}$ & Rotor outer/inner diameter. \\
\hline $\boldsymbol{L}_{\boldsymbol{s}}, \boldsymbol{L}_{\boldsymbol{r}}$ & Dimension of stator/rotor \\
\hline $\boldsymbol{T}_{\boldsymbol{s}}, \boldsymbol{a}_{\boldsymbol{s}}$ & No of stator turns/phase; C.S. of stator conductor \\
\hline $\boldsymbol{l}_{\boldsymbol{g}}$ & Length of air-gap \\
\hline $\boldsymbol{a}_{\boldsymbol{b}}, \boldsymbol{l}_{\boldsymbol{b}}$ & Cross-section/ length of rotor bar \\
\hline $\boldsymbol{I}_{\boldsymbol{\mu}}, \boldsymbol{I}_{\boldsymbol{w}}, \boldsymbol{I}_{\mathbf{0}}$ & Magnetizing/ core and friction loss/ no load current \\
\hline
\end{tabular}




\section{CONSTRUCTIONAL FEATURES OF INDUCTION MOTOR}

Induction motors are broadly classified as squirrel-cage type and phase-wound or slip-ring type [1]. The squirrel-cage types are more robust and rugged, cheaper and maintenancefree. So, they are more in common use. However, they were not suitable for variable speed drive (until the advent of power electronic control). They run at a lagging power factor thus drawing substantive amount of VAR from the system causing excessive voltage drop. They are also not suitable for loads requiring high starting torque. The phase-wound or slip-ring types are used for such drives though they are more expensive and they suffer from problems arising out of rotating contacts [2], [3]. The individual phase windings are similar to each other- they are internally separate but externally connected in star or delta according to the designer's choice [5]. Copper conductors of appropriate cross section are used. Aluminum conductors are used for transmission lines but are not suitable for rotating machines as they take more space which offsets the overall economy.

\section{ROTOR CONSTRUCTION}

The rotor core is comprised of the same material laminations with varnish coatings to reduce eddy current. Solid cores, on the other hand, are employed in huge machines to make rotors that are mechanically stronger. Rotor iron loss is minimal since the rotor frequency is substantially lower than the line frequency. The number of slots should not be identical to the number of stator slots, and there should be no unfavorable stator-rotor slot combinations to prevent vibration, noise, cogging, and crawling[6].

\subsection{Cage-typemotors}

Stator construction: The main parts of the stator are the stator core and the stator windings. The core- coil structure is assembled in the frame. The frame sizes are standardized. The stator core is made by assembling stampings of Si-steel (Lohys or special Lohys) having one or two coats of varnish. Different grades of materials are available in the market. Semi closed slots, either parallel-sided or rectangular, are commonly used. Depending on the size of the motor, a no. of radial and axial ducts is provided while cores are assembled, for adequate cooling and if necessary a cooling fan is also added. The slots are lined with insulating paper and coils made. The cage type rotor is made by placing bars of copper or aluminum in the slots and brazing them to two endrings. Presently die-cast rotors are used which mechanically stronger, aluminum is being the commonly used material [7]. The cage type rotor is short-circuited in itself. Hence no resistance can be inserted in the rotor circuit of a cage type motor to limit the starting current and increase the starting torque. Larger starting torque may be realized by using deep and narrow slots or by using double squirrel cage construction [8]. The rotor core and winding structure are keyed to a specified diameter M.S. shaft, which is mounted on ball/roller bearings in end-plates fastened to the stator frame on both sides. The diameter is obtained by taking torsional and bending forces into account. The enclosure should be chosen based on the environment, and the mounting should be based on the intended application.

\subsection{Phase-Wound motors}

The phase-wound or slip-ring type motors are used for adjustable speed drives. Their stator construction is similar to that of squirrel-cage motor. But the rotor construction is different, it houses a polyphone winding wound for same no. of poles (but may be of different no. of phases) as for the stator. The windings are connected in star and the terminals brought to slip-rings. Variable rheostats are connected to the windings through slip-rings and brushes. Their function is to limit the starting current and to increase the starting torque. They may also be used for rheostatic speed control. However, slip-power recovery schemes employing power-electronic devices are better options as they do not waste power in the rheostats and hence they are power-economic. They can be used also in the VAR-compensating mode by injecting emf with q-axis components. 


\section{THE DESIGN PROCEDURE}

The engineering equipment is designed using four distinct approaches: analytic, synthetic, optimum, and standard. The logical technique is highly common and perhaps too straightforward. It starts with identifying the plan factors and assigning appropriate standard values to them. These figures are derived from the designer's experience or from design data books. Then, for the equipment to be designed, data is entered. The software goes through a series of stages to calculate the machine's dimensions and compute the performance characteristics. There is no such regenerative feedback from the reaction or results in the excitation section. As a result, one must be satisfied with whatever outcomes he obtains or take another chance by modifying the design variables' values [9], [14]. The hyper surface of the cost function has been discovered to be concave after executing the program. Using this information, we conducted a sequential gradient search on the selected design variables and were able to achieve the minimum in a substantially reduced number of steps. The inadequacies in the logical access can be partly counterbalance by the subsequent artificial technique in which features and limitations are given. To provide several regenerative feedbacks from the response in aspect of limitations and to deliver forthcoming modifications in the parameters to adjust to the particulars [10], [11] the specific application is intended. Accordingly, the technique has been viewed as extremely viable by inquiring for the ideal.

\subsection{Designvariables}

To design a 3-phase induction motor several values of parameters is essential. Few of them are considered as in the form of parameters, i.e., constant, selection and integer parameter [12], [17]. The parameters that have major importance on the cost estimation and are named as key parameters. The corresponding slot layout, single coated or dual coated stator winding, bearing category, laminated or solid rotor and substance for rotor conductor etc. are considered as a selection parameters. The corresponding quantity of slots/pole/phase (usually integral slot winding is utilized in an induction motor, quantity of stator/rotor slots, quantity of ducts and quantity of conductors/slot (even integer for dual layer winding) etc. are considered as a integer parameters [13].Initially the key parameters or factors are determined. Hence, at that point, they are instated. Their esteems are altered steadily to achieve the most feasible or ideal planning. Several considerable parameters don't come into scenario in viewpoint of standard planning e.g., the quantity of stator/rotor slots, slots/pole/phase, slot deepness/slot thickness etc. and so on as these are characterized by the standard stratification to be utilized [15], [19].

\subsection{Design Constraints}

The optimization has to be sought in presence of a no of inequality and other constraints viz.

- Full voltage starting torque/full load torque must more than a pre-defined value e.g.,1.75.

- Maximum torque/full load torque must more than a pre-defined value e.g.,2.25.

- The efficiency must be more than a pre-defined value e.g., $85 \%$

- The power factor must be more than a pre-defined value e.g., 0.8lagging

- The no. of stator slots/ rotor slots must be integers

- No. of slots/pole/phase must be an integer

\section{ALGORITHM}

With standard stratification the algorithm for optimum design is as follows:

1. Read only information on design parameters $\left(B_{a v}, a c, L / \tau\right)$, exact cost etc.

2. Read only information files on SWG no of conductors, depth of insulation etc.

3. Read features or specifications of the motor.

4. Check the sustainability of the specifications. For inacceptable specifications go to step2.

5. Observe the output coefficient. Find apparent power/ input power from expected values of power factor \&efficiency.

6. Find the windage loss \& estimated friction by implementing in formation file on the same. 
7. Find quantity of poles, synchronous. Speed and the $D^{2} L$ product.

8. Find shaft dimension from mechanical deliberations.

9. Select dimension /pole pitch ratio as 0.8 and find the stator bore dimension.

10. Open the data file for standard laminations available in the market and keep the data in an array. Compare the calculated diameter with the diameters of standard laminations and choose the frame size of nearest available diameter.

11. Read the details of the lamination. Check the feasibility of accommodating the shaft. If the inner diameter of the lamination is less than the shaft diameter then go to step33.

12. Find the length of stator from $D^{2} \mathrm{~L}$ product, net length of iron, number of ducts, pole pitch and flux per pole.

13. Find pitch factor by short pitching the coil to about $5 / 6^{\text {th }}$ of the pole pitch. Find the breadth factor and the winding factor.

14. Find number of turns/phase.

15. Find stator current, cross-section of the wire and no. of wires in connected in parallel.

16. Open the information file for SWG number and choose the particular wire available in the marketplace.

17. Find the external diameter of the wire and deepness of insulation.

18. Choose semi-closed slots and parallel-sided teeth.

19. Find thickness of teeth and deepness of stator core for specified flux density of core and the teeth.

20. Find the slot dimensions to arrange the wires.

21. Find mean distance of turn of stator and its resistance per phase.

22. Compute iron loss in teeth \& core of the stator by opening information file on distinct LOHYS.

23. Find the air gap and rotor dimensions.

24. Choose Aluminium as rotor conductor substance. Find dimensions of the rotor bars and the end rings and sizes of the rotor slots.

25. Find Carter's coefficients from the data file and the total AT of stator, rotor \&air-gap.

26. Find the no load current and magnetization current.

27. Find the overhang, zigzag presences, slot leakage and the leakage reactance.

28. Find the short circuit impedance and rotor resistance.

29. Make performance assessment at full load-efficiency-slip-power factor and temperature rise.

30. Find maximum torque and critical speed.

31. Find starting current and starting torque, taking for enhancing the rotor resistance due to skin effect into considerations.

32. Calculate the weight of aluminum, copper and iron and find the total cost estimation including of overhead \& labour cost.

33. Save all estimated values in array.

34. Lessening the diameter by one step \& go to step11.

35. Inspect the calculated values of the array and choose the stratification for cost-optimality.

36. Print the values consistent to optimal design.

37. Stop.

38. End.

In this study, the cost function comprises the working cost of the motors in accumulation to its capital cost to conserve the interest of the consumer. 


\subsection{Flow Chart}

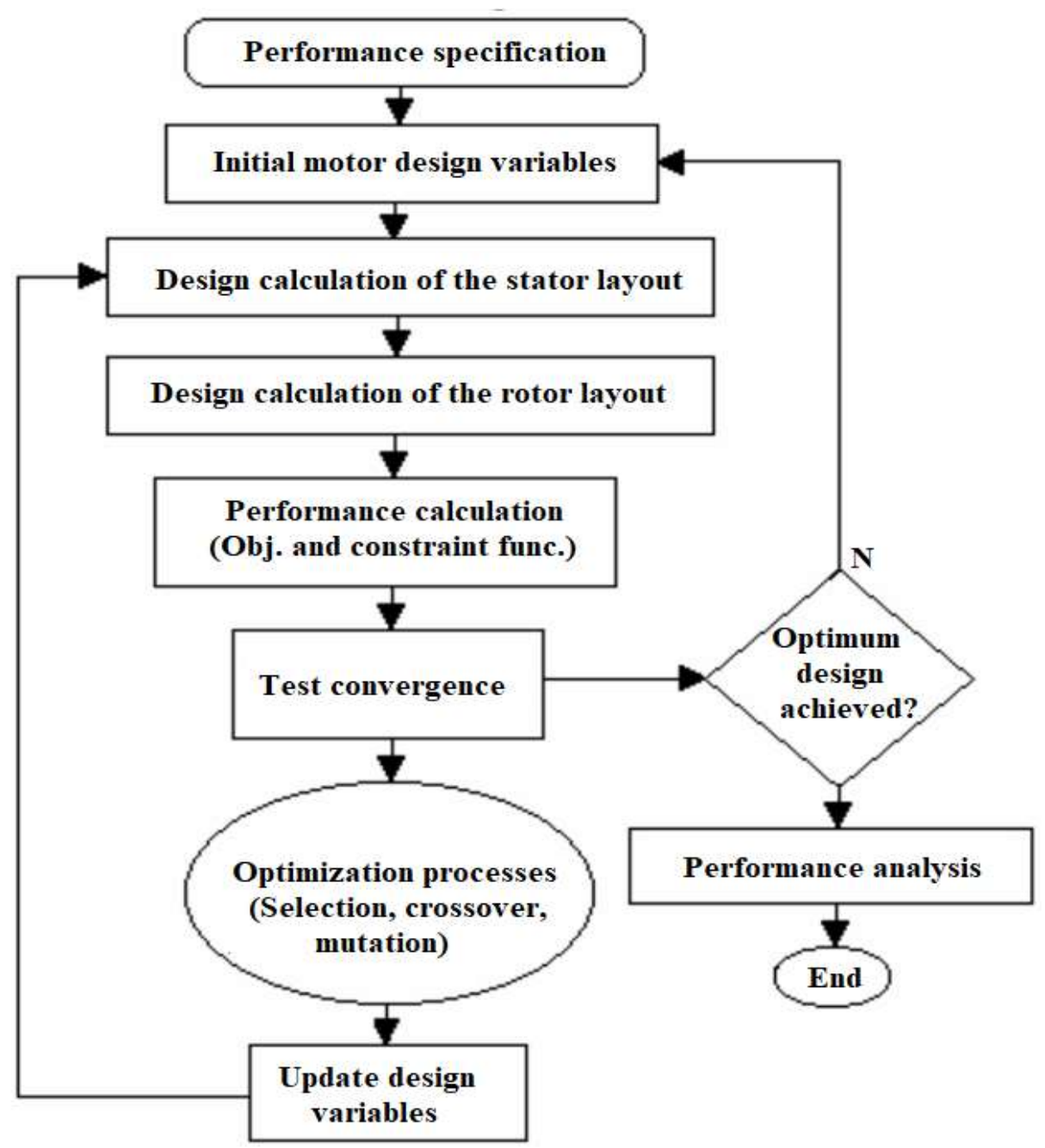

Figure 1. The flow chart for design optimization process [20]

\section{CASE STUDY}

A programme has been designed to design the motor using standard stampings, adjusting design factors such, $\mathrm{L} / \tau$ ratio etc. and compute the cost function. This function is a weighted combination of the cost of production and the running cost so as to cover the interest of both the producer and the consumer [16], [17], [18]. The design has been made on the basis of above algorithm and flow chart. The first case-study has been developed via hybrid technique (analytic + synthetic). Then, 2nd case-study has been developed by running specifically designed software to attain the optima. The following solutions have been reached.

\subsection{The Specifications}

Category of motor: 3-phase Squirrel Cage Induction motor

Category of starter: Star-Delta (Yd)

Frame Substance: Normalized Grey C.I., with holes for axial flow.

Stator winding construction: DELTA; Type of stator winding: Double layer

Slot insulation: Bonded Polyester; Stator/ Rotor core substance: Super-varnished Special

Lohys Class of insulation: B: Temperature growth as per grade

Category of enclosure: SPDP with fan-cooling

Stator conductor material: Synthetic resin-enameled copper

Rotor substance: Die-cast Aluminum; Roller bearings on each ends: Rotor to be dynamically stable. 


\subsection{The Ratings}

$\mathrm{KW} / \mathrm{HP}$ (output) $=30 / 40.2$; Line voltage $=415 \mathrm{~V}$;

Difference: $-15 \%$ to $+6 \%$ Frequency $=50$ Hz. difference: $\pm 4 \%$; R.P.M. $=1450$;

Duty: Incessant

Constraints: both efficiency and P.F at full load $\geq 0.85$; no load current $\leq 30 \%$;

Temp. rise of stator $\leq 50^{\circ} \mathrm{C}$; max. Torque/full load torque $\geq 2.5$.

\subsection{Chosen Design Variables Andassumptions}

Ampere-conductor $/ \mathrm{m}=35000$;

Average flux-density $=0.45$ Tesla, Length/pole-pitch ratio changing from: 0.8 to 2

Stator current density $=6 \mathrm{~A} / \mathrm{mm} 2$, Rotor current density $=4.575 \mathrm{~A} / \mathrm{mm} 2$

Stator teeth $/$ core density in Tesla: $=1.2,1.25$ Rotor core density $=0.6627$ Tesla

Copper space factor $=0.6$, Expected efficiency /power factor: 0.9 / 0.9

\subsection{The Precisecosts}

Cost of iron $=$ Rs. $120 / \mathrm{Kg}$.

Cost of copper $($ nomex-coated $)=\mathrm{Rs} 720 / \mathrm{Kg}$.

Cost of aluminum $=$ Rs. $180 / \mathrm{Kg}$.

\subsection{The Findings}

The programme finds out the following possibilities:

Table 2: Stampings against different frame number

\begin{tabular}{|c|c|c|c|c|l|}
\hline Frame no. & $\begin{array}{c}\text { Stator outer } \\
\text { diam, mm. }\end{array}$ & $\begin{array}{c}\text { Stator inner } \\
\text { diam, mm. }\end{array}$ & $\begin{array}{c}\text { Rotor inner } \\
\text { diam, mm. }\end{array}$ & $\begin{array}{l}\text { Stator no. } \\
\text { of slots }\end{array}$ & $\begin{array}{l}\text { Rotor no. } \\
\text { of slots }\end{array}$ \\
\hline 144M & 260.4 & 177.8 & 44.45 & 36 & 40 \\
\hline 102M & 304.8 & 190.5 & 50.8 & 36 & 40 \\
\hline 146M & 304.8 & 215.9 & 50.8 & 36 & 40 \\
\hline 104M & 366.6 & 228.6 & 50.8 & 36 & 59 \\
\hline 103AM & 355.6 & 254.0 & 50.8 & 48 & 59 \\
\hline
\end{tabular}

Out of these given in the above Table:2for different stampings against frame number the $104 \mathrm{M}$ of Shankey division of GKW gives the cost-optimal solution. So the design of two case studieshas been made on the basis of thisstamping.

\section{MAIN DIMENSIONS FOR BOTH CASE STUDIES}

No. of poles $=4$.

Synchronous speed $=25$ R.P.S Approx.

KW/KVA input=33.3/37.

Output coefficient $=164.59$.

D2L-product $=0.00900 \mathrm{~m} 3$.

We choose standard stampings from table1, but slots are freely designed.

The frame designation chosen by iterative procedure: 104M.

\subsection{Performance Calculation of Two Case Studies}

Table3: Performance Calculation of Case Study:1(Hybrid approach)

\begin{tabular}{|c|c|c|c|c|}
\hline $\mathbf{I}_{\mathbf{F L}}$ (Amp.) & $\mathbf{T}_{\mathbf{F L}}(\mathbf{N}-\mathbf{m})$ & $\mathbf{P . F}$ & $\mathbf{N}_{\mathbf{F L}}(\mathbf{R P M})$ & Efficiency (\%) \\
\hline $\mathbf{5 2 . 2 3}$ & 211.34 & 0.425 & 1435 & 87.55 \\
\hline $\mathbf{5 2 . 5 1}$ & 211.72 & 0.468 & 1435 & 87.56 \\
\hline $\mathbf{5 2 . 7 9}$ & 211.98 & 0.499 & 1435 & 87.56 \\
\hline $\mathbf{5 3 . 2 3}$ & 212.25 & 0.532 & 1436 & 87.68 \\
\hline $\mathbf{5 3 . 4 6}$ & 212.54 & 0.566 & 1437 & 87.85 \\
\hline $\mathbf{5 3 . 8 2}$ & 212.88 & 0.588 & 1438 & 87.89 \\
\hline $\mathbf{5 4 . 0 5}$ & 213.31 & 0.634 & 1439 & 88.92 \\
\hline
\end{tabular}




\begin{tabular}{|l|c|c|c|c|}
\hline $\mathbf{5 4 . 3 8}$ & 213.67 & 0.668 & 1440 & 88.96 \\
\hline $\mathbf{5 4 . 6 7}$ & 213.96 & 0.687 & 1441 & 89.01 \\
\hline $\mathbf{5 4 . 8 4}$ & 214.41 & 0.741 & 1442 & 89.22 \\
\hline $\mathbf{5 4 . 9 6}$ & 214.87 & 0.787 & 1443 & 89.30 \\
\hline $\mathbf{5 5 . 3 2}$ & 215.21 & 0.816 & 1445 & 89.44 \\
\hline $\mathbf{5 5 . 5 6}$ & 215.86 & 0.857 & 1448 & 89.76 \\
\hline $\mathbf{5 5 . 8 3}$ & 216.42 & 0.888 & 1450 & 89.97 \\
\hline $\mathbf{5 5 . 9 8}$ & 216.89 & 0.936 & 1453 & 90.11 \\
\hline $\mathbf{5 6 . 2 8}$ & 217.36 & 0.987 & 1455 & 90.18 \\
\hline $\mathbf{5 5 . 8 8}$ & 216.81 & 0.942 & 1454 & 90.01 \\
\hline $\mathbf{5 5 . 5 4}$ & 216.39 & 0.911 & 1452 & 89.96 \\
\hline $\mathbf{5 5 . 1 5}$ & 215.82 & 0.872 & 1450 & 89.80 \\
\hline
\end{tabular}

Table 4: Performance Calculation of Case Study:2 (Optimal solution)

\begin{tabular}{|c|c|c|c|c|}
\hline $\mathbf{I}_{\text {FL }}(\mathbf{A m p .})$ & $\mathbf{T}_{\mathbf{F L}}(\mathbf{N}-\mathbf{m})$ & $\mathbf{P . F}$ & $\mathbf{N}_{\text {FL }}(\mathbf{R P M})$ & Efficiency (\%) \\
\hline $\mathbf{4 5 . 6 6}$ & 196.52 & 0.468 & 1436 & 87.79 \\
\hline $\mathbf{4 5 . 8 9}$ & 196.94 & 0.497 & 1437 & 87.83 \\
\hline $\mathbf{4 6 . 3 3}$ & 197.48 & 0.542 & 1437 & 87.89 \\
\hline $\mathbf{4 6 . 3 7}$ & 197.87 & 0.569 & 1438 & 88.94 \\
\hline $\mathbf{4 6 . 9 9}$ & 198.21 & 0.598 & 1439 & 88.96 \\
\hline $\mathbf{4 7 . 3 6}$ & 198.54 & 0.634 & 1440 & 89.13 \\
\hline $\mathbf{4 7 . 6 4}$ & 198.91 & 0.668 & 1441 & 89.32 \\
\hline $\mathbf{4 7 . 9 2}$ & 199.36 & 0.697 & 1443 & 89.40 \\
\hline $\mathbf{4 8 . 3 8}$ & 199.74 & 0.741 & 1445 & 89.44 \\
\hline $\mathbf{4 8 . 8 6}$ & 199.99 & 0.781 & 1447 & 89.76 \\
\hline $\mathbf{4 9 . 1 4}$ & 200.46 & 0.830 & 1449 & 89.97 \\
\hline $\mathbf{4 9 . 3 7}$ & 200.71 & 0.857 & 1450 & 90.15 \\
\hline $\mathbf{4 9 . 7 0}$ & 200.97 & 0.881 & 1452 & 90.54 \\
\hline $\mathbf{4 9 . 9 8}$ & 201.22 & 0.924 & 1454 & 90.69 \\
\hline $\mathbf{5 0 . 1 7}$ & 201.69 & 0.959 & 1456 & 90.91 \\
\hline $\mathbf{5 0 . 3 9}$ & 202.12 & 0.993 & 1459 & 91.36 \\
\hline $\mathbf{5 0 . 0 7}$ & 201.98 & 0.961 & 1457 & 91.11 \\
\hline $\mathbf{4 9 . 7 9}$ & 201.51 & 0.934 & 1455 & 90.89 \\
\hline $\mathbf{4 9 . 6 2}$ & 201.13 & 0.899 & 1453 & 90.67 \\
\hline
\end{tabular}

\section{PERFORMANCE CHARACTERISTICS FOR BOTH CASE STUDIES}
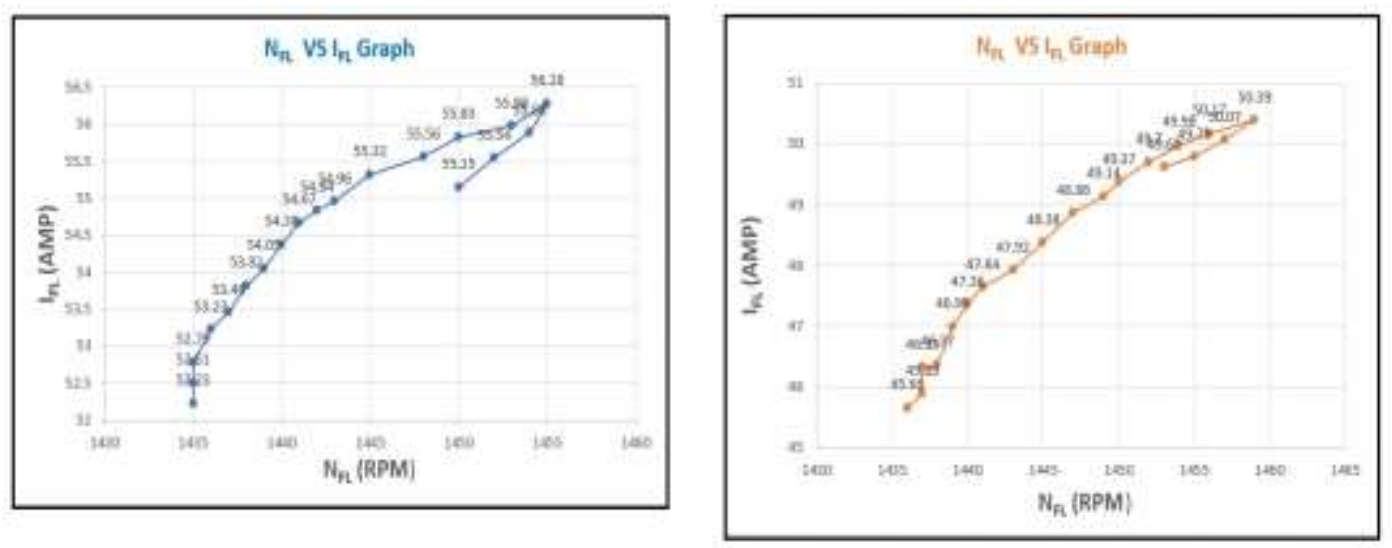

Figure 2. a) NFL VS IFL response for hybrid approach. Figure 2. b) NFL VS IFL response for optimal 


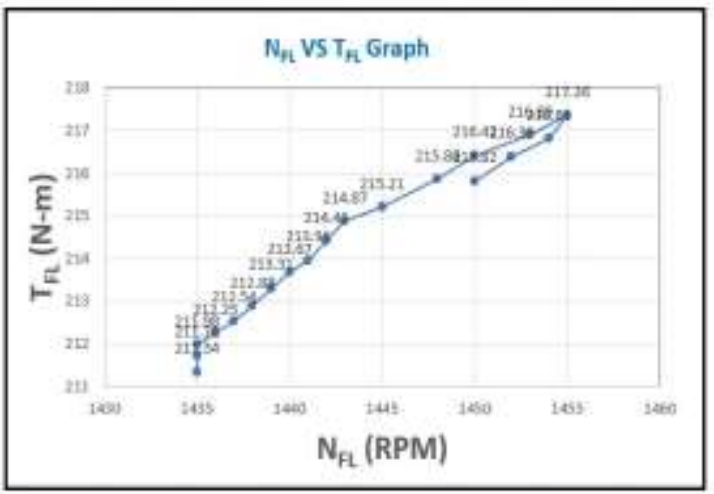

Figure 2.c) NFL VS TFL response for hybrid approach.

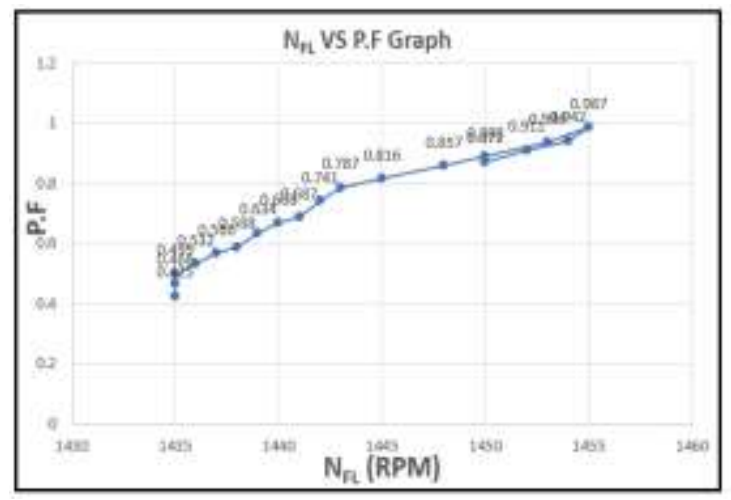

Figure2. e) NFL VS P.F response for hybrid approach.

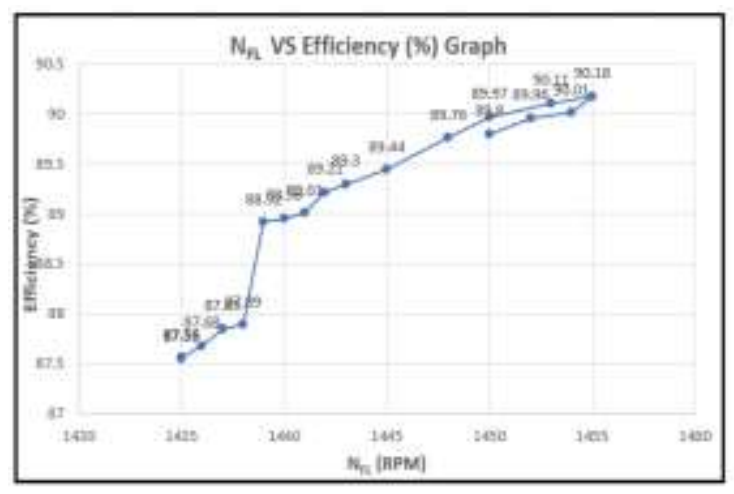

Figure 2. g) NFL VS efficiency (\%) response for for hybrid approach.

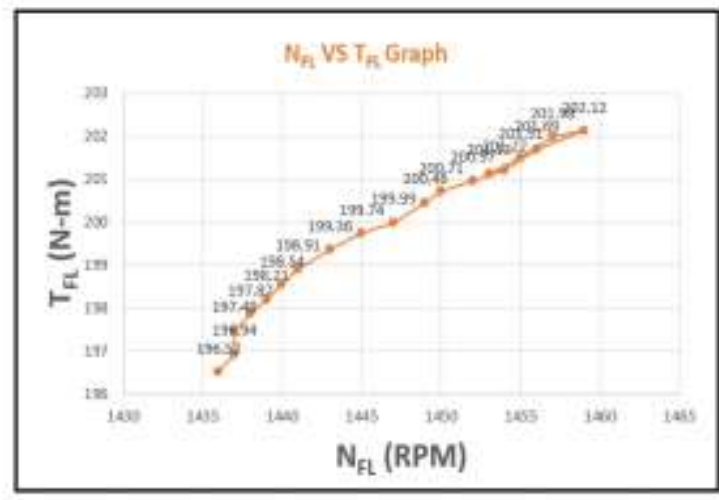

Figure 2. d) NFL VS TFL response for optimal solution.

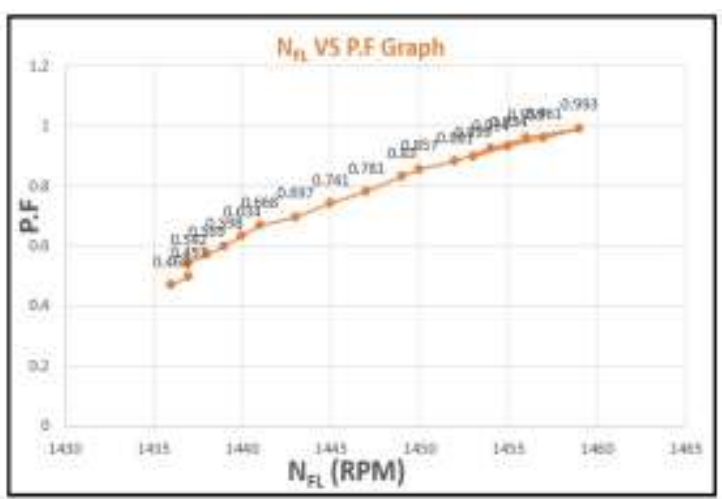

Figure 2f) NFL VS P.F response for optimal solution

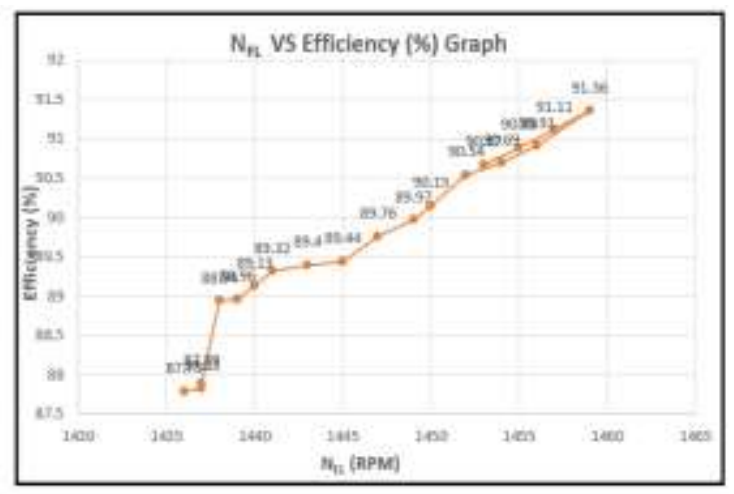

Figure 2. h) NFL VS efficiency (\%) response optimal solution.

Figure: 2 Performance Characteristics:

Fig. (2a) \&Fig. (2b) Full load Current (IFL) -- Full load Speed (NFL) for both case studies, Fig.(2c) \&Fig. (2d) Full load Torque (TFL) -- Full load Speed (NFL) for both case studies, Fig.(2e) \&Fig. (2f) Full load PF -- Full load Speed (NFL) for both case studies,

Fig.(2g) \&Fig. (2h) Full load Efficiency -- Full load Speed (NFL) for both case studies, Fig. (2a),(2c),(2e),(2g) : Case Study 1 (Hybrid approach)

Fig. (2b),(2d),(2f),(2h) : Case Study 2 (Optimal solution)

Figure 2 depicts examples of performance characteristics of both case studies and fouroptimumdesigns (IFL, TFL, PF \& Efficiency) as a function of the speed and observed from performance calculation of case study $1 \&$ case study 2 that, the best results of full load current, full load torque, full load PF, full load efficiency and full load speed are given below in Table: 5 . 
Table 5: Best results of Performance calculation

\begin{tabular}{|l|c|c|}
\hline \multicolumn{1}{|c|}{ Equipment/Item of the IM } & Case study: $\mathbf{1}$ & Case study: $\mathbf{2}$ \\
\hline Full load condition: Full load torque & $217.36 \mathrm{~N}-\mathrm{m}$ & $202.12 \mathrm{~N}-\mathrm{m}$ \\
\hline Full load line current & $56.28 \mathrm{Amp}$. & $50.39 \mathrm{Amp}$. \\
\hline Full load power factor & 0.987 & 0.993 \\
\hline Full load efficiency & 0.9018 & 0.9136 \\
\hline Full load speed & $1455 \mathrm{RPM}$ & $1459 \mathrm{RPM}$ \\
\hline
\end{tabular}

\section{COMPARE BETWEEN TWO CASE STUDIES}

CASE STUDY 1: Hybrid approach (Analytic + Synthetic) Chosen design variables [Form Text books ([3], [4]) \&designer's experience]

CASE STUDY 2: Optimal solution

Table 6: Stator Design

\begin{tabular}{|l|c|c|}
\hline Equipment/Item of the IM & Case study: 1 & Case study: 2 \\
\hline Stator bore diameter in mm & 282.3 & 228.6 \\
\hline Stator length in mm & 182 & 17 \\
\hline Length/pole-pitch ratio & 0.897 & 0.793 \\
\hline Quantity of ducts & 1 & 1 \\
\hline Width of ducts in mm & 10.3 & 10 \\
\hline Net length of iron in mm & 159 & 147 \\
\hline Pole pitch in mm & 187.5 & 179.4 \\
\hline Flux/pole in weber & 0.397 & 0.374 \\
\hline No. of stator slots/ no. of rotor slots & $54 / 78$ & $36 / 59$ \\
\hline Stator slot angle & 20 & 20 \\
\hline Quantity of stator/rotor slots/pole/phase & $3 / 5.32$ & $3 / 4.91$ \\
\hline Stator/rotor slot pitch in mm & $20.3 / 11.7$ & $19.8 / 11.7$ \\
\hline Pitch factor of stator & 0.964 & 0.985 \\
\hline Breadth factor of stator & 0.933 & 0.959 \\
\hline Winding factor of stator & 0.936 & 0.945 \\
\hline No of conductors/slot & 36 & 24 \\
\hline Total no. of conductors & 924 & 864 \\
\hline No of turns/phase & 154 & 144 \\
\hline No of parallel conductors in stator & 2 & 2 \\
\hline SWG No. of stator conductors & 17 & 15 \\
\hline Area of stator conductor in mm2 & 2.89 & 2.63 \\
\hline Diameter of stator conductor in mm & 1.98 & 1.83 \\
\hline $\begin{array}{l}\text { Diameter of stator conductor with insulation in } \\
\text { mm }\end{array}$ & 2.76 & 2.06 \\
\hline Total copper area/slot in mm2 & 138.7 & 126.08 \\
\hline Width of teeth in mm & 9.45 & 8.5 \\
\hline Lip / Wedge in mm & $1 / 3$ & $1 / 3$ \\
\hline Width of slot over wedge in mm & 14.4 & 12.1 \\
\hline Width of slot at bottom in mm & 19 & 16 \\
\hline Depth of slot in mm & 29 & 26 \\
\hline Actual copper space factor & 0.608 & 0.407 \\
\hline Deepness of stator core in mm & 39 & 37 \\
\hline External diameter of stator in mm & 373 & 356 \\
\hline Clearance with frame in mm & 4.3 & 4 \\
\hline
\end{tabular}


Table 7: Rotor Design

\begin{tabular}{|l|c|c|}
\hline \multicolumn{1}{|c|}{ Equipment/Item of the IM } & Case study: $\mathbf{1}$ & Case study: $\mathbf{2}$ \\
\hline Air gap length in mm & 0.88 & 0.6 \\
\hline Rotor length in mm & 178 & 160 \\
\hline Rotor bar current in Amp. & 366.6 & 370.6 \\
\hline Rotor bar area in mm & 87 & 81 \\
\hline Rotor bar width in mm & 4.8 & 4.5 \\
\hline Rotor bar length in mm & 172.5 & 160.5 \\
\hline Rotor bar depth in mm & 19.5 & 18 \\
\hline Slip-ring width in mm & 25 & 21 \\
\hline Depth of rotor core in mm & 78.2 & 70.4 \\
\hline Inner diameter of rotor or Shaft diameter & 58.8 & 50.8 \\
\hline Tooth height in mm & 6.7 & 6.3 \\
\hline Minimum width of rotor teeth in $\mathbf{m m}$ & 6.3 & 5.7 \\
\hline
\end{tabular}

Flux-density \& Width of rotor teeth at $1 / 3^{\text {rd }}$ for both case studies.

Rotor bars are skewed by one slot pitch, Ring depth is equal to bar dept. for both case studies.

Table 8: No Load Current Calculation

\begin{tabular}{|l|c|c|}
\hline \multicolumn{1}{|c|}{ Equipment/Item of the IM } & Case study: 1 & Case study: 2 \\
\hline Carter's coefficient: for stator slot & 0.787 & 0.637 \\
\hline Carter's coefficient: for duct & 0.871 & 0.763 \\
\hline Carter's coefficient: rotor slot & 0.284 & 0.253 \\
\hline Space contraction factor: for stator slot & 1.2 & 1.19 \\
\hline Space contraction factor: for rotor slot & 1.14 & 1.02 \\
\hline Gap contraction factor: for duct & 1.347 & 1.047 \\
\hline Equivalent gap contraction factor & 1.569 & 1.272 \\
\hline Turn required for air gap & 384 & 372 \\
\hline Stator teeth & 102 & 92 \\
\hline Rotor teeth & 11 & 9 \\
\hline Stator core & 37 & 31 \\
\hline rotor core & 4 & 4 \\
\hline Total Amp. Turn required & 542 & 508 \\
\hline Magnetizing currentin Amp. & 6.37 & 6.63 \\
\hline Friction \& Windage Losses in Watt & 552 & 522 \\
\hline Stator teeth & 147 & 130 \\
\hline Stator core in watt & 247.2 & 229.4 \\
\hline Stator iron in watt & 366.5 & 359.8 \\
\hline Iron Loss in watt & 1.7 & 1.1 \\
\hline Rotational loss current in Amp. & $0.78,2.51 \%$ & $0.71,2.43 \%$ \\
\hline No load currentin Amp. & 6.41 & 6.69 \\
\hline Rotor ohmic loss in watt & $888.3,2.93 \%$ & $867.6,2.64 \%$ \\
\hline Stator ohmic loss in watt & $1138.2,3.43 \%$ & $1088.3,3.31 \%$ \\
\hline No load loss in watt & $897.32,2.87 \%$ & $881.83,2.69 \%$ \\
\hline Total loss in watt & $2923.82,9.23 \%$ & $2837.73,8.64 \%$ \\
\hline
\end{tabular}


Table 9: Parameter estimation

\begin{tabular}{|l|c|c|}
\hline \multicolumn{1}{|c|}{ Equipment/Item of the IM } & Case study: 1 & Case study: $\mathbf{~}$ \\
\hline Stator resistance & 0.658 & 0.508 \\
\hline Rotor resistance referred to stator & 0.537 & 0.405 \\
\hline Eddy loss ratio & 6.334 & 5.724 \\
\hline Leakage reactance: due to slotting & 1.67 & 1.15 \\
\hline Due to overhang & $0.48 \Omega$ & $0.40 \Omega$ \\
\hline Due to zigzag & $0.97 \Omega$ & $0.92 \Omega$ \\
\hline Total leakage reactance & $3.33 \Omega$ & $2.47 \Omega$ \\
\hline Magnetizing reactance & $69.4 \Omega$ & $65.1 \Omega$ \\
\hline Iron loss resistance & $617.34 \Omega$ & $585.91 \Omega$ \\
\hline Equivalent impedance referred to stator & $2.974 \Omega$ & $2.638 \Omega$ \\
\hline Full load condition: Full load torque & $217.36 \mathrm{~N}-\mathrm{m}$ & $202.12 \mathrm{~N}-\mathrm{m}$ \\
\hline Full load condition: Full load stator current/phase & $34.17 \mathrm{Amp}$. & $29.09 \mathrm{Amp}$. \\
\hline Full load line current & $56.28 \mathrm{Amp}$. & $50.39 \mathrm{Amp}$. \\
\hline Full load power factor & 0.987 & 0.993 \\
\hline Full load power input & $33263 \mathrm{Watt}$ & $32838 \mathrm{Watt}$ \\
\hline Full load efficiency & 0.9018 & 0.9136 \\
\hline Full load slip & 0.0283 & 0.0273 \\
\hline Full load speed & $1455 \mathrm{RPM}$ & $1459 \mathrm{RPM}$ \\
\hline Starting current & $113 \mathrm{Amp}$. & $110.5 \mathrm{Amp}$. \\
\hline Starting torque at full voltage & $554.67 \mathrm{~N}-\mathrm{m}$ & $540.31 \mathrm{~N}-\mathrm{m}$ \\
\hline Starting torque at reduced voltage (Y-D starter) & $187.38 \mathrm{~N}-\mathrm{m}$ & $180.1 \mathrm{~N}-\mathrm{m}$ \\
\hline full load current for full voltage starting & 3.987 & 3.796 \\
\hline full load torque for full voltage starting & 2.827 & 2.673 \\
\hline full load torque at reduced voltage (Y-D starter) & 0.888 & 0.891 \\
\hline Critical slip & 0.16326 & 0.16037 \\
\hline Maximum torque & $543.25 \mathrm{~N}-\mathrm{m}$ & $541.96 \mathrm{~N}-\mathrm{m}$ \\
\hline $\begin{array}{l}\text { Temperaturerise:Copperlossinembedded portion } \\
\text { ofstatorwinding }\end{array}$ & $437.1 \mathrm{Watt}$ & $419.1 \mathrm{Watt}$ \\
\hline Total loss in embedded portion of stator winding & $789.6 \mathrm{Watt}$ & $778.9 \mathrm{Watt}$ \\
\hline Temperature rise of stator & $29.37^{0} \mathrm{C}$ & $32.68^{0} \mathrm{C}$ \\
\hline
\end{tabular}

Table10: Cost Analysis

\begin{tabular}{|l|c|c|}
\hline \multicolumn{1}{|c|}{ Equipment/Item of the IM } & Case study: 1 & Case study: $\mathbf{2}$ \\
\hline Weight of iron in Kg & 97.38 & 90.65 \\
\hline Cost of iron in Rs. & $11686 /-$ & $10877 /-$ \\
\hline Weight of copper in Kg & 19.87 & 17.83 \\
\hline Cost of copper in Rs. & $14306 /-$ & $12841 /-$ \\
\hline Mass of Aluminium in Kg & 3.34 & 2.87 \\
\hline Price of Aluminium in Rs. & $601 /-$ & $517 /-$ \\
\hline Material cost including 20\% Auxiliaries in Rs. & $29083 /-$ & $29083 /-$ \\
\hline $\begin{array}{l}\text { Manufacturing cost inclusive of Labour\& } \\
\text { Establishment in Rs. }\end{array}$ & $40716 /-$ & $40716 /-$ \\
\hline Total Cost in Rs. & $\mathbf{9 6 3 9 2 / -}$ & $\mathbf{9 4 0 3 4 / -}$ \\
\hline
\end{tabular}


Table11: Check against Specs

\begin{tabular}{|l|llll|l|l|l|}
\hline Item & $\begin{array}{l}\text { Speed } \\
(\mathbf{R P M})\end{array}$ & $\begin{array}{l}\text { Efficiency } \\
\text { atF.L, } \\
(\mathbf{\%})\end{array}$ & $\begin{array}{l}\text { P.F at } \\
\text { F.L, } \\
(\mathbf{l a g})\end{array}$ & $\begin{array}{l}\text { Temp. } \\
\text { rise, } \\
\left({ }^{\circ} \mathbf{C}\right)\end{array}$ & $\begin{array}{l}\text { No load } \\
\text { Current, } \\
(\text { Amp. })\end{array}$ & $\begin{array}{l}\text { Max } \\
\text { Torque at } \\
\text { F.L } \\
(\mathbf{N}-m)\end{array}$ & $\begin{array}{l}\text { Selling } \\
\text { Cost, } \\
(\mathbf{R s .})\end{array}$ \\
\hline Hybrid & 1455 & 90.18 & 0.987 & 29.37 & 6.41 & 543.25 & $\mathbf{9 6 3 9 2 / -}$ \\
\hline Optimal & 1459 & 91.36 & 0.993 & 32.68 & 6.69 & 541.96 & $\mathbf{9 4 0 3 4 / -}$ \\
\hline
\end{tabular}

It may be noted that all the specs have been fulfilled in both the cases, but the overall cost is much lower in the optimal design approach.

\section{CONCLUSION}

Optimization is the process of selecting the best possible answer from a large number of options. A design problem's possible solutions are discovered by altering the design variables within their usual boundaries. Comprehensive exploration in the variable-section, as well as processes such as gradient search, stochastic walk methodology, and so on, may be used to find the explanation with the lowest cost. Because a smaller number of explanations is used, high-level numerical approaches are not required for finding the best explanation using common limits. In this regard, the approach of extensive inquiry is appropriate in this case. It is particularly crucial in terms of assessing the resemblance of that system architecture, including the chosen normal core, and whether or not the details have been met. If we believe that the goal will be met at the lowest possible cost, this will be extremely advantageous for equipment assembly and manufacturing. It will keep the machine's cost low while increasing the selling, vending, or trading value. In any event, the machines will be less effective, have larger ohmic and no-load losses, and inadvertently cause more environmental pollution. As a result, the optimal approach is to define a true objective function that represents both the capital and operating expenses. A PC software was created for the design of a $30 \mathrm{KW}, 415 \mathrm{~V}$, 3-phase squirrel-cage induction motor in this study.It's worth noting that the specifications for both the hybrid and optimum approaches were met. However, there is a significant price difference between the two. In comparison to the best design, the hybrid method costs Rs. 2338/- more. In terms of efficiency, no-load current, and power factor, there isn't much of a difference. The ideal scenario has a lower slip. As a result of this research, it is clear that the design of power electrical equipment should always be based on optimality in today's competitive market. By appropriately altering the goal function, the cost optimality can be adjusted or extended to the optimality of selected design characteristics, such as maximum torque, efficiency, or power factor. 


\section{REFERENCES}

[1] Anderson, O.W. (1967). Optimum design of electrical machines. IEEE Trans. (PAS), $86,707-11$.

[2] Ramamoorty, M. (1987). Computer-aided design of electrical equipment. Affiliated East-West Press Pvt. Ltd. ISBN: 81-85095-57-4

[3] Say, M.G. (2002). Performance and design of a.c. machines. CBS. ISBN-13:9788123910277

[4] Sawhney, A.K. (2003). A course in electrical machine design. DhanpatRai andSons,

[5] K. Deb, (2010).Optimization for engineering design. PHI. ISBN978-81-203-0943-2

[6] Rao, S.S. Engineering optimization- theory and practice. New Age International. ISBN 978-81- 224-2723-3

[7] N.S. Kambo, (1984). Mathematical programming techniques. Affiliated East-West Press Pvt.Ltd. New Delhi - 110 001, ISBN 81-85336-47-4.

[8] Shanmugasundaram, A, Gangadharan, G, Palani, R, Electrical machine design data book. Wiley Eastern Ltd. ISBN 0852268130

[9] Lindsay,S.F,Barton,T.H.(1996).Parameteridentificationforsquirrelcageinductionmachine s.IEEE Transaction Power Apparatus System,92(1),1287-1291.

[10] Erajskar, G, Bhattacharyya, M, Mahendra, S.N.(1974). Computer-aided design of three Phase squirrel cage induction motor technical design, hybrid process and optimization.I.I.E(India), E.E. Div., India, 2-50.

[11] Pragati S. Ramteke, Rahul P. Argelwar, April, (2016), Speed Control of Three Phase Induction by Phase Angle Control of TRIAC, Journal of Network Communications and Emerging Technologies (JNCET) www.jncet.org Volume 6, Issue 4, ISSN: 2395-5317 (C)Ever Science Publications: 11.

[12] Z. Guo, J. Zhang, Z. Sun, and C. Zheng, (2017) "Indirect Field Oriented Control of Three-Phase Induction Motor Based on Current-Source Inverter," Procedia Engineering, vol. 174, pp. 588- 594.

[13] AbdülhamitNurettin, Nihatinanç (2021), Proceedings of Engineering and Technology Innovation, vol. 19, pp. 01-15 Hybrid Speed Controller Design Based on Sliding Mode Controller Performance Study for Vector Controlled Induction Motor Drives.

[14] Ertan, H.B, Aykanat, C. A new approach to optimized design of induction motor.Dept.of Elect. Engg., Middle East Technical university, Ankara, Turkey.

[15] Kentli, F. A survey of design optimization studies of induction motor during the last decade. Department of Electrical Engineering Education, Marmara University, Goztepe, Istambul, Turkey.

[16] Hasanah, R.N. Energy saving through design optimization of induction motor (2009). Journal EECCIS,3(1).

[17] Thanga,C. R, Srivastava, S.P, Agarwal,P,(2009). Energy-efficient control of threephase induction motor - a review. International Journal of Computer and Electrical Engineering.1(1).

[18] Kannan,R., Bhuvaneswari,R., Subramanian,S. (2007). Optimal design of three-phase induction motor using Particle swarm Optimization, Iranian Journal of Electrical and Computer Engineering, 6(2).

[19] Sivaraju, S. S., Devarajan, N.(2011)Novel design of three phase induction motor enhancing efficiency, maximizing power factor and minimizing losses. European Journal of Scientific Research. 58(3), ISSN1450-216X, 423-432.

[20] Mehmet Çunkaş, RamazanAkkaya, (2006) Design optimization of induction motor by genetic algorithm and comparison with existing motor, Mathematical and Computational Applications, Vol. 11, No. 3, pp. 193-203. 